OPEN ACCESS

Edited by:

Marijn Lijffijt,

Baylor College of Medicine,

United States

Reviewed by:

Scott Zeller,

University of California, Riverside,

United States

Valeria Latorre,

ASLBari - Azienda Sanitaria

Localedella provincia di Bari

(ASL BA), Italy

*Correspondence:

Veronica B. Searles Quick veronica.searlesquick@ucsf.edu

Specialty section:

This article was submitted to

Psychopharmacology,

a section of the journal

Frontiers in Psychiatry

Received: 31 July 2021 Accepted: 10 November 2021 Published: 07 December 2021

Citation:

Searles Quick VB, Herbst ED and Kalapatapu RK (2021) Which Emergent Medication Should I Give

Next? Repeated Use of Emergent Medications to Treat Acute Agitation.

Front. Psychiatry 12:750686.

doi: 10.3389/fpsyt.2021.750686

\section{Which Emergent Medication Should I Give Next? Repeated Use of Emergent Medications to Treat Acute Agitation}

\author{
Veronica B. Searles Quick*, Ellen D. Herbst and Raj K. Kalapatapu \\ Department of Psychiatry and Behavioral Sciences, University of California, San Francisco, San Francisco, CA, United States
}

Agitation is a common symptom encountered among patients treated in psychiatric emergency settings. While there are many guidelines available for initial management of the acutely agitated patient, there is a notable dearth of guidelines that delineate recommended approaches to the acutely agitated patient in whom an initial medication intervention has failed. This manuscript aims to fill this gap by examining evidence available in the literature and providing clinical algorithms suggested by the authors for sequential medication administration in patients with persistent acute agitation in psychiatric emergency settings. We discuss risk factors for medication-related adverse events and provide options for patients who are able to take oral medications and for patients who require parenteral intervention. We conclude with a discussion of the current need for well-designed studies that examine sequential medication options in patients with persistent acute agitation.

Keywords: agitation, psychiatry, emergency, sequential, repeated, medication

\section{INTRODUCTION}

Agitation is a common presenting or comorbid condition among patients in psychiatric emergency settings (1) and exists on a continuum of severity, ranging from irritability to violence (2-4). Concurrent with management of symptoms, attempting to identify the etiology of acute agitation is crucial for guiding ongoing treatment $(5,6)$. Recognizing and managing acute agitation effectively is essential to maintaining both patient and staff safety (7), and first-line management starts with verbal de-escalation (8).

When behavioral approaches alone are insufficient, pharmacologic interventions may be required. A significant portion of acutely agitated patients, though, do not respond to initial pharmacologic interventions $(7,9-12)$. An understanding of what medications may be safely administered in a sequential fashion is thus a fundamental component of acute agitation management protocols. While multiple guidelines are available that discuss first-line medications for acute agitation $(7,9,13,14)$, there is limited guidance regarding steps one should take pharmacologically when an initial medication has failed (15).

This manuscript aims to assist clinicians with managing patients with persistent acute agitation in psychiatric emergency settings by bridging the gap in the literature on this topic. Our focus is on pharmacological management of persistent acute agitation when sequential medications are needed. We discuss oral (PO), inhalational and intramuscular (IM) routes of administration, as these are most commonly available in psychiatric emergency settings. Using available evidence 
in the literature, we provide our own potential clinical algorithms for managing patients with persistent acute agitation and conclude with future research recommendations.

\section{CURRENT TREATMENT GUIDELINES FOR ACUTE AGITATION}

There is a substantial body of literature reviewing safety and efficacy of medications for acute agitation from which expert consensus guidelines have been developed. A representative sample of recent guidelines are provided in Table 1, which demonstrate that even among expert bodies, there is no consensus regarding any single medication that should be used first-line to manage acute adult agitation. This variability across expert recommendations is likely driven by studies to date demonstrating that multiple approaches appear to be efficacious for managing agitation. Additionally, many current guidelines have not been revised for years and do not incorporate newer medication options, more comprehensive data regarding side effects, or the importance of certain prophylactic agents that are now considered standard of care (16).

\section{REPEATED USE OF EMERGENT MEDICATIONS: GENERAL CONSIDERATIONS}

Table 2 highlights key factors to consider when deciding to administer sequential medication to treat persistent acute agitation. Staff members should have adequate training in identification and non-pharmacologic management of acute agitation $(8,17)$. Whenever a patient is being evaluated for necessity of medication, standardized measures to assess acute agitation severity should be utilized (18). Reassessment time points should be clearly defined (e.g., every $15 \mathrm{~min}$ ), as should the goal time period to achieve calm (e.g., $45-60 \mathrm{~min}$ ). The goal of treating acute agitation with medication should be calmness, not oversedation or obtundation from medication combinations $(19,20)$.

When a patient is unable to consent to medication, a restraint checklist should be used to reduce the risk that bias or provider limitations are impacting the decision to administer medications in an emergency setting (21). Oral pharmacological formulations are effective $(22,23)$ and should be utilized whenever possible prior to consideration of use of IM medications. If the IM route is indicated, staff must be properly trained in injection technique to avoid unpredictable absorption patterns and inadequate response (24).

Patient characteristics such as age and sex are important for informing treatment decisions. Certain medications are relatively contraindicated in elderly individuals due to an increased risk of adverse events in this age group $(25,26)$. Pediatric populations necessitate a multimodal approach with modified dosing (27), and only a subset of discussed medications are considered appropriate for use in pregnant patients (28).

A thorough history, review of medical conditions and current medications, and physical examination is important, although often not possible at the initial assessment time point due to the severity of agitation and should be reattempted when appropriate to do so. Assessing recent substance use is critical to ensure accurate diagnosis and mitigate interactions between substances and medications used to treat acute agitation.

Combining medications with similar side effect profiles may increase risk for adverse effects, and during sequential dosing, close attention should be paid to what a patient has already received to avoid or mitigate these cumulative risks. Documentation of the expected time to effect of medications already administered (29) and likelihood of requiring subsequent dosing $(30,31)$ can help avoid premature dosing and polypharmacy.

Current evidence from research examining first-line interventions should guide sequential medication selection $(7,9,14,29,32-34)$. Evidence-based antipsychotics for acute agitation include loxapine, haloperidol, droperidol, olanzapine, risperidone, ziprasidone, aripiprazole, and asenapine (13, 3553). Evidence-based benzodiazepines for acute agitation include midazolam and lorazepam $(29,32,33,54,55)$. In the United States (U.S.), IM droperidol and midazolam are not typically used in psychiatric emergency settings unless embedded in medical emergency departments due to monitoring requirements.

Current guidelines counsel against co-administration of IM olanzapine and IM lorazepam, although some have argued the risk associated with such is overstated (56) or most relevant for patients with alcohol intoxication given elevated risk of respiratory depression in this population $(57,58)$. Promethazine and diphenhydramine have also been used in combination with antipsychotics to treat acute agitation (31, $42,59)$. Evidence is lacking to support the combination use of a first-generation antipsychotic (FGA), anticholinergic and benzodiazepine concurrently (60). Compared to antipsychotics and benzodiazepines, ketamine has a greater incidence of adverse events when used for acute agitation $(61,62)$ and should be avoided in psychiatric emergency settings.

\section{REPEATED USE OF EMERGENT MEDICATIONS: CURRENT EVIDENCE}

There is limited evidence examining specific sequential medication options for managing persistent acute agitation, although many studies examining initial medications allowed for rescue sedation if indicated. One contributor to this limited evidence may be the United States Food and Drug Administration's restrictions on conducting clinical trials of agitation $(63,64)$. The majority of studies examining initial interventions for acute agitation did not evaluate associations between sequential dosing or polypharmacy and efficacy or adverse events. We summarize notable findings, while emphasizing limitations on interpretation.

In a prospective observational study of 1,403 participants receiving IM droperidol (65), 31\% of participants received additional sedation including droperidol, midazolam, ketamine, diazepam and dexmedetomidine. Oversedation was significantly 
TABLE 1 | Guidelines and consensus statements regarding pharmacologic interventions for agitation.

\section{Guideline Overview of recommendations}

American Association for Emergency Psychiatry Project BETA

Psychopharmacology Workgroup Consensus Statement (9)
Published in 2012 and followed by many practitioners in the United States

Recommendations stratified by suspected etiology of agitation:

Patients with a known psychiatric disorder:

PO: risperidone or olanzapine; haloperidol+benzodiazepine second-line.

IM: olanzapine or ziprasidone; haloperidol+benzodiazepine second-line

Authors note to avoid haloperidol+benzodiazepines if contraindications to such exist, but do not provide a clearly delineated summary

of contraindications

Patients with depressant intoxication:

Haloperidol monotherapy (PO or IM)

Avoid benzodiazepines due to risk of respiratory depression.

Patients with stimulant intoxication or alcohol withdrawal:

Benzodiazepine monotherapy (PO or IM)

Agitation associated with delirium, where depressant withdrawal is not suspected:

PO: risperidone or olanzapine; haloperidol at low dose second-line

IM: olanzapine or ziprasidone, or haloperidol IM or IV, with caveat that if IV is $>3 \mathrm{mg} /$ day to monitor closely for EPS, and IV haloperidol requires continuous cardiac monitoring.

British Association for Psychopharmacology and the National Association of Psychiatric Intensive Care and Low Secure Units: Evidence-based consensus guidelines for the clinical management of acute disturbance (14)

\section{Published in 2018}

Not stratified by suspected etiology of agitation

PO/inhaled/buccal recommendations:

Oral-inhaled loxapine (bronchodilator should be available), aripiprazole, olanzapine, risperidone, haloperidol (baseline ECG advised), buccal midazolam and oral quetiapine.

Guideline recommends against clonazepam and diazepam due to risk of adverse effects, and levopromazine given lack of evidence. Lorazepam and promethazine are described as possibly effective.

IM monotherapy recommendations:

Aripiprazole, droperidol (baseline ECG advised), olanzapine (avoid co-administration with benzodiazepines due to risk of sedation, respiratory depression and hypotension)

Guideline recommends avoiding haloperidol monotherapy due to risk of EPS, lorazepam and diazepam due to lack of evidence, midazolam due to risk of respiratory depression, and levopromazine due to risk of cardiovascular adverse events including hypotension. IM combination therapy recommendations:

Promethazine or lorazepam plus haloperidol (baseline ECG recommended)

Guidelines recommend against combining promethazine with lorazepam due to lack of evidence.

World Federation of Societies of Biological Psychiatry: Agitation Consensus (7)

\section{Published in 2016}

Authors state it is not possible to make very specific evidence-based pharmacologic recommendations based on available studies, thus provide a series of consensus statements to be considered by practitioners:

Lorazepam and first-generation antipsychotics are similar in efficacy.

Agitation due to psychosis should be treated with lorazepam with an antipsychotic. Consensus also states the evidence for adding benzodiazepines to an antipsychotic is inconclusive.

IM second-generation antipsychotics are not inferior to haloperidol, albeit with a different side effect profile.

Agitation due to alcohol withdrawal should be treated with benzodiazepines.

Agitation due to alcohol intoxication should be treated with antipsychotics.

Elderly patients should be treated with lower doses.

New formulations are promising (e.g., inhaled loxapine).
Brazilian guidelines for the management of psychomotor agitation (13)
Published in 2019

Recommendations stratified by etiology of agitation and other factors:

Patients with depressant intoxication:

PO: haloperidol

IM: haloperidol

Patients with stimulant intoxication or depressant withdrawal:

PO: diazepam, clonazepam, or lorazepam

IM: midazolam

IV: midazolam or diazepam

If agitation in these patients is severe, consider PO risperidone or IM haloperidol.

Patients with psychiatric disorder:

PO: risperidone, risperidone+lorazepam, asenapine, or olanzapine

IM: haloperidol+promethazine, haloperidol+midazolam, droperidol, or haloperidol

Patients with delirium:

PO: risperidone

IM: haloperidol

If ETOH withdrawal: benzodiazepines

Elderly patients:

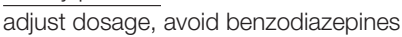




\begin{tabular}{ll}
\hline Guideline & Overview of recommendations \\
\hline PO: risperidone or olanzapine \\
IM: haloperidol \\
Pregnant patients: \\
\hline PO: risperidone \\
IM: haloperidol \\
Repeat until reaching dosing limits, then if needed, switch medication. \\
Authors recommend avoiding IV route, and monitoring subjects before and after drug administration. Avoid antipsychotics and parenteral \\
routes if known cardiac risk factors.
\end{tabular}

ECG, electrocardiogram; EPS, extrapyramidal symptoms; ETOH, alcohol; IM, intramuscular; IV, intravenous; PO, oral.

TABLE 2 | General considerations when selecting emergent medications for repeated use.

\begin{tabular}{ll}
\hline Demographics & Age \\
& Sex \\
History & Allergies \\
& Comorbid psychiatric disorder(s) \\
& Comorbid substance use disorder(s) \\
& Comorbid medical disorder(s) \\
& Severity of behaviors \\
& Collateral information \\
& Unknown/1st-time patient vs. known patient \\
& Direct arrival from community vs. staying in facility \\
Objective & Standardized measure of acute agitation such as a rating scale \\
findings & Laboratory results such as urine toxicology \\
& Electrocardiogram \\
& Vital signs \\
& Height and weight \\
& Physical examination \\
& Level of staff training in acute agitation identification \\
and verbal de-escalation techniques \\
Soncurrent \\
safety \\
interventions
\end{tabular}

associated with three or more attempts at sedation (but not if droperidol was the only medication used), and with the use of benzodiazepines. Five percentage of participants experienced other adverse events (hypotension and respiratory depression were the most common).

A randomized controlled trial (RCT) of 167 participants receiving IM midazolam, olanzapine or haloperidol allowed for repeated dosing and alternative medications (66). Of participants receiving midazolam, 23\% received a second dose, and $16 \%$ received alternative medication; of those receiving olanzapine, $28 \%$ received a second dose, and $11 \%$ received alternative medication; of those receiving haloperidol, $32 \%$ received a second dose, and $12 \%$ received alternative medication. There was one episode of dystonia and one fatal cardiac arrest in the haloperidol arm, the latter of which was thought partially due to stimulant intoxication.

In a prospective observational study of 2011 participants examining IM olanzapine, haloperidol, and zuclopenthixol $(12,67), \leq 67 \%$ of participants required at least one additional dose of medication, and $62.7 \%$ received $\geq 2$ antipsychotics during the acute phase. Participants initially receiving IM olanzapine had fewer adverse events and required fewer anticholinergics/anxiolytics. Sedation was common, and haloperidol was associated with extrapyramidal symptoms (EPS). Another observational study examining olanzapine (68) allowed for sequential dosing with additional parenteral medications. $10 / 489$ participants receiving the IM formulation experienced respiratory depression, including five requiring intubation.

One RCT of 270 participants examining repeated IM olanzapine dosing compared to repeated dosing of IM haloperidol or placebo found that haloperidol was associated with greater incidence of EPS (69); those randomized to olanzapine $10 \mathrm{mg}$ or haloperidol required fewer doses. Another RCT of 300 participants receiving IM olanzapine or IM haloperidol and promethazine found that the olanzapine group required more additional dosing (43 vs. $21 \%$ ), and there were no significant between-group differences in EPS (59). An RCT of 488 participants receiving IM haloperidol, aripiprazole or placebo, allowed up to 3 injections/24h (70); the haloperidol group had greater incidence of EPS. An RCT of 376 participants comparing sequential dosing of IM ziprasidone and haloperidol found ziprasidone was associated with fewer adverse events, and haloperidol associated with greater incidence of EPS (71).

A retrospective study of 15,918 participants received IM droperidol, olanzapine, and haloperidol examined rescue sedation requirements (31). Haloperidol was associated with greater use of rescue sedation medications. Forty nine 


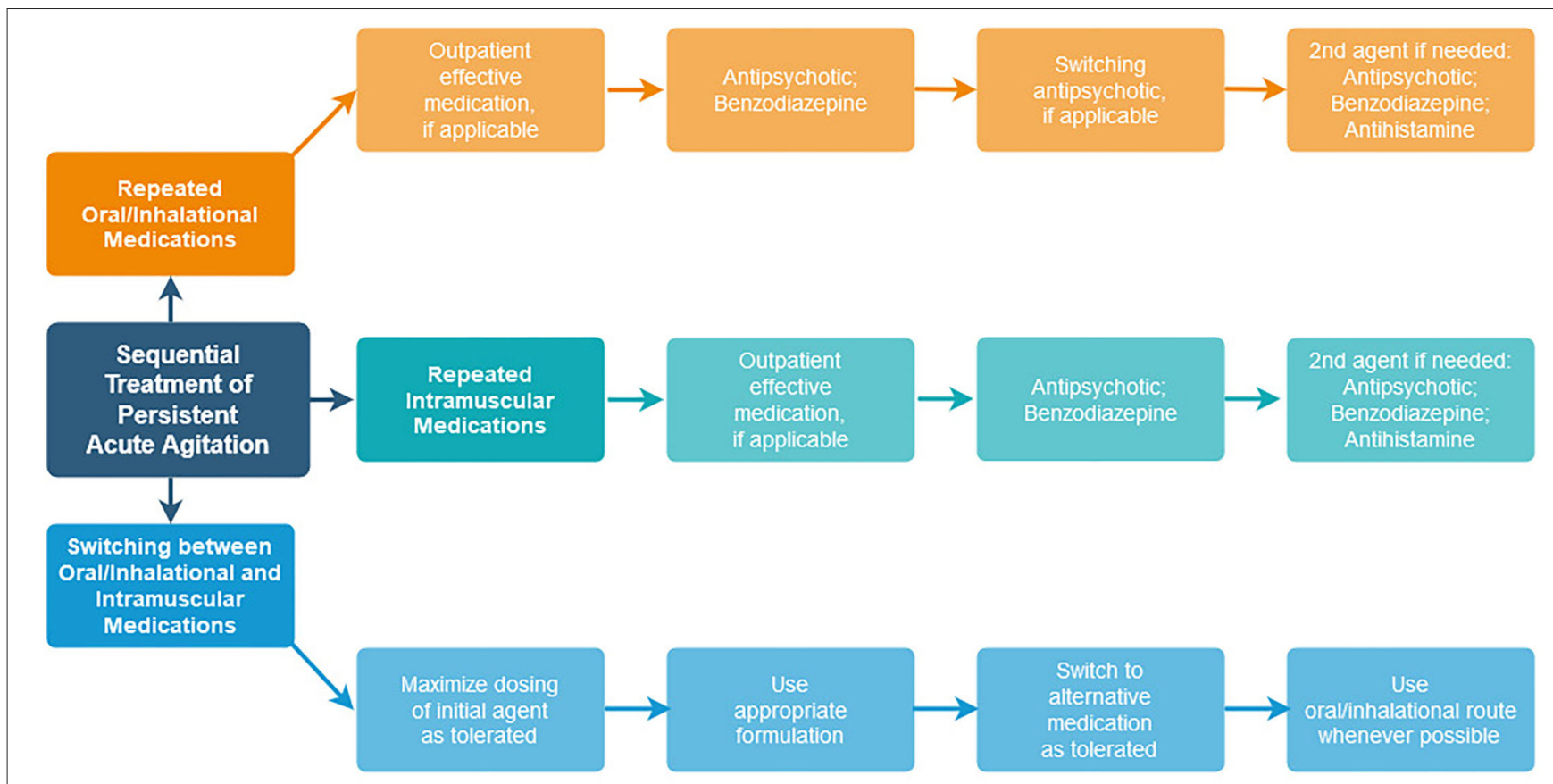

\section{For all scenarios at each medication step:}

monitor vital signs, assess for side effects, re-assess acute agitation severity, re-attempt behavioral interventions, assess for physical restraints, assess for calmness, avoid combinations that prolong QTC interval, maximize dosing as tolerated, proceed with extra caution if $>8$ rounds of medications, re-assess for non-psychiatric medical causes of agitation, transfer to emergency department if indicated

FIGURE 1 | Sequential treatment algorithms for persistent acute agitation.

intubations were documented; one fatality occurred in a participant who received olanzapine, haloperidol, and ketamine and was later found to have a subarachnoid hemorrhage. A prospective study examining IM ziprasidone, midazolam, haloperidol and olanzapine found $20-40 \%$ of 737 participants required sequential dosing (30). There were four intubation events, but no association between such and specific medication combinations received was reported.

An RCT of 115 participants comparing IM droperidol, lorazepam, and ziprasidone (72) and allowing for rescue sedation noted lower respiratory depression with droperidol than with ziprasidone or lorazepam. An RCT of 359 participants comparing inhaled loxapine and IM aripiprazole found that repeat administrations of both were well-tolerated, loxapine had a faster onset, and participant satisfaction was higher in the loxapine-treated group (73). An RCT of 344 participants examining repeated dosing of inhaled loxapine found that administration of two to three doses of 5-10 mg each was well-tolerated and efficacious (74). An RCT of 124 participants found sequential dosing of risperidone (total 24$\mathrm{h}$ dose $>6 \mathrm{mg}$ ) was associated with EPS (43). A retrospective analysis of 388 participants found that repeated dosing of IM antipsychotics, but not PO antipsychotics, was associated with a longer length of stay in the psychiatric emergency department (11).
Overall, while numerous studies of acute agitation management have allowed sequential medication administration, few have assessed what risks are associated with specific sequential options. Risks that have been reported include increased cardiac risk from combining QTc prolonging agents and more common known side effects with higher doses of specific agents (e.g., EPS when haloperidol is administered without an agent for EPS prophylaxis). The incidence of serious events (intubation, serious arrhythmia, or death) are quite rare even when multiple medications are used concurrently. A study of 904 participants to comprehensively assess risk factors for adverse events found that administering multiple medications within a 60-min period, alcohol intoxication, and age $>65$ were associated with adverse events (25), suggesting sequential medication use does increase risk of adverse events and should be used cautiously.

\section{DISCUSSION: SEQUENTIAL TREATMENT ALGORITHM}

Since the need for guidance remains surrounding how to approach sequential medications in practice, we offer our own suggested sequential treatment algorithms (Figure 1) for persistent acute agitation that are consistent with data 
from available studies, using agents that are available in the United States.

Since polypharmacy is one of the main predictors of adverse events (25), an approach that focuses on limiting polypharmacy should be prioritized. Assessment of acute agitation severity using a standardized measure (18) should be completed at each time point. Behavioral interventions should be re-attempted prior to consideration of subsequent medication administration. Vital sign and side effect monitoring should be done to reduce risk of adverse events. Oral routes should be utilized over parenteral routes when possible. The goal of intervention should be to assist the patient in achieving a state of calmness, not oversedation or obtundation from medication combinations. At each step, consider expected time to onset of the medication being used, and take this into account when determining how soon another dose may be needed (32). At each step, continue to assess whether a non-psychiatric medical condition is causing or contributing to continued agitation, and whether transfer to a medical emergency department might be indicated.

\section{Scenario \#1: Repeated Use of Oral/Inhalational Medications}

This situation arises when a patient only agrees to the oral route, and acute agitation is not severe enough to justify involuntary parenteral medication administration. Which medication is most appropriate at a specific step is based on considerations in Tables 1, 2.

Step 1

a. If the first medication trialed was an antipsychotic, and the patient is not experiencing side effects with such, then continuing to titrate the initial medication trialed may be appropriate if there was an indication of any noticeable effect from the first dose given.

b. If the first medication trialed was a benzodiazepine, given the risk of oversedation with this class, repeated dosing of such should be approached with caution. For mild acute agitation in a patient without risk factors for a substance use disorder, and who is tolerating the initial dose well without side effects, one could consider an additional dose of the first agent used.

c. If the decision is made to switch to an antipsychotic, then olanzapine, ziprasidone, risperidone, loxapine, asenapine, and haloperidol are all reasonable options to consider with evidence to support their use, although haloperidol has a higher risk for EPS and should be administered with an agent for EPS prophylaxis. Inhalational loxapine should only be used if a bronchodilator is readily accessible and should be avoided in patients with pre-existing lung disease.

d. If it becomes known that the patient is on an effective medication as an outpatient, one may consider switching to this medication to treat acute agitation.

Step 2-If the patient continues to meet acute agitation criteria and re-attempts of behavioral interventions are insufficient, trial another dose of the same agent, while continuing to monitor for side effects and response. Maximize dosing as tolerated and indicated of the first agent prior to moving to Step 3.
Step 3

a. If the patient continues to have poor acute agitation control, sufficient time for effectiveness has been given, behavioral interventions continue to be insufficient, and acute agitation severity continues to necessitate pharmacologic intervention, one may consider another agent, guided by what has already been administered and taking into account considerations in Table 2.

b. Options include an antipsychotic (either if this was not trialed in Step 1, or if the dose of the first agent was maximized and the patient is exhibiting psychosis that would argue for continuing an antipsychotic approach), an antihistamine, or a benzodiazepine. Keep in mind the relatively higher risk for oversedation with a benzodiazepine and that with increasing polypharmacy, risk of side effects is increased.

c. Avoid combining agents that carry significant risk for QTc prolongation.

d. Maximize dosing as tolerated before moving to Step 4 .

Step 4

a. With each additional medication administered, the risk of adverse events to the patient increases. Continue to assess acute agitation severity using structured measurements to determine whether additional medication is necessary and to reattempt behavioral interventions.

b. Consider whether physical restraints are needed to provide safety while waiting for medications to take effect, prior to increasing polypharmacy burden.

c. If $>3$ rounds of medications continue to be necessary, proceed with extra caution at each step while reassessing acute agitation severity, monitoring vital signs and side effects, reattempting behavioral interventions, and monitoring for calmness.

\section{Scenario \#2: Repeated Use of Intramuscular Medications}

This situation arises when a patient does not consent to oral medication and acute agitation is severe enough to justify involuntary parenteral medication. Whenever it becomes possible to do so, switch to the oral route unless the patient expresses preference for continued use of IM formulation. As in scenario \#1, which medication is most appropriate at a specific step is based on considerations in Tables 1, 2 .

Step 1

a. If the patient initially received an antipsychotic and is tolerating such, administer an additional dose of the first medication received if there was an indication of any noticeable effect from the first dose given.

b. If the patient initially received a benzodiazepine, given the risk of oversedation with this class, repeated dosing of such should be approached with caution.

c. If the decision is made to use an antipsychotic, Olanzapine IM is a reasonable choice for acute agitation management, but should not be administered within one hour of IM lorazepam. IM droperidol is also a reasonable choice, although 
monitoring requirements in the US limit its use in psychiatric emergency settings that are not embedded in medical emergency departments. If using ziprasidone, haloperidol or droperidol, the risk for QTc prolongation should be considered, and if using haloperidol, it should be administered with an agent for EPS prophylaxis.

d. If it becomes known that the patient is on an effective medication as an outpatient and there is an IM formulation of such, consider an additional dose of this medication via IM, staying within single and total daily dose limits.

Step 2-Follow the same approach as Step 2 in Scenario 1. Consider whether medication has been given sufficient time to take effect.

Step 3-Follow the same approach as Step 3 in Scenario 1. As above, note prior medications the patient has received thus far to avoid adverse events. If IM ziprasidone or haloperidol or droperidol has been used, avoid other agents with QTcprolonging properties. Maximize dosing as tolerated prior to moving to Step 4.

Step 4-Follow the same approach as in Step 4 above.

\section{Scenario \#3: Switching Between Oral/Inhalational and Intramuscular Medications}

This situation arises when a patient initially agrees to the oral route as described in Scenario \#1, but then declines the oral route (or becomes unable to tolerate such), or when a patient who is initially declining an oral medication (as described in Scenario \#2) becomes amenable to a PO route.

In each case, if the patient has not maximized the dose of the initial agent received, and there is an appropriate formulation of such, continue to use this medication. If the patient has reached the maximum daily dose, or the medication is not available in the formulation needed, switch to an alternative medication. As in the previous scenarios, which medication is most appropriate is based on considerations in Tables 1, 2.

\section{REFERENCES}

1. Boudreaux ED, Allen MH, Claassen C, Currier GW, Bertman L, Glick R, et al. The Psychiatric Emergency Research Collaboration01: methods and results. Gen Hosp Psychiatry. (2009) 31:515-22. doi: 10.1016/j.genhosppsych.2009.04.009

2. Vieta E, Garriga M, Cardete L, Bernardo M, Lombraña M, Blanch J, et al. Protocol for the management of psychiatric patients with psychomotor agitation. BMC Psychiatry. (2017) 17:328. doi: 10.1186/s12888-017-1490-0

3. Iozzino L, Ferrari C, Large M, Nielssen O, de Girolamo G. Prevalence and risk factors of violence by psychiatric acute inpatients: a systematic review and meta-analysis. PLOS ONE. (2015) 10:e0128536. doi: 10.1371/journal.pone.0128536

4. Sachs GS. A review of agitation in mental illness: burden of illness and underlying pathology. J Clin Psychiatry. (2006) 67(Suppl. 10):5-12. doi: $10.1383 /$ psyt.2006.5.1.10

5. Nordstrom K, Zun LS, Wilson MP, Stiebel V, Ng AT, Bregman B, et al. Medical evaluation and triage of the agitated patient: consensus statement of the american association for emergency psychiatry project Beta medical evaluation workgroup. West J Emerg Med. (2012) 13:3-10. doi: 10.5811/westjem.2011.9.6863

\section{CONCLUSION}

This paper aims to fill a gap in the acute agitation literature regarding how to treat persistent acute agitation in psychiatric emergency settings when an initial medication has failed. Given the paucity of studies in this area, it is not possible to provide a single best-practices algorithm for management. The suggestions we put forth are our own clinical suggestions and are created from available data gleaned from studies of initial medication interventions for acute agitation. The general principle of using the lowest effective dose (starting at low doses and providing adequate time to effect between doses) applies, as well as incorporating new information as it becomes available to guide treatment. Aiming to achieve a state of calmness, but not oversedation or obtundation from medication combinations, should be prioritized as additional medications are added over a multi-hour timeframe. Similarly, assessment of vital signs, side effects, treatment response, and utility of behavioral interventions should be undertaken at each time point that a sequential medication is being considered. Future research in this area is clearly needed, including formal testing of repeated medications using explicit algorithms (e.g., redosing with the same medication vs. switching medications), with subsequent comprehensive analyses of associations between specific sequential options and both treatment response and adverse events.

\section{AUTHOR CONTRIBUTIONS}

VS completed the background literature search and wrote the first draft of the article. All authors have approved the final article.

\section{FUNDING}

VS was supported by the National Institute of Mental Health grant R25MH06048.

6. Stowell KR, Florence P, Harman HJ, Glick RL. Psychiatric evaluation of the agitated patient: consensus statement of the American Association for emergency psychiatry project Beta psychiatric evaluation workgroup. West J Emerg Med. (2012) 13:11-6. doi: 10.5811/westjem.2011.9.6868

7. Garriga M, Pacchiarotti I, Kasper S, Zeller SL, Allen MH, Vázquez $\mathrm{G}$, et al. Assessment and management of agitation in psychiatry: expert consensus. World J Biol Psychiatry. (2016) 17:86-128. doi: 10.3109/15622975.2015.1132007

8. Richmond JS, Berlin JS, Fishkind AB, Holloman Jr GH, Zeller SL, Wilson MP, et al. Verbal de-escalation of the agitated patient: consensus statement of the American Association for emergency psychiatry project BETA De-escalation workgroup. West J Emerg Med. (2012) 13:17-25. doi: 10.5811/westjem.2011.9.6864

9. Wilson MP, Pepper D, Currier GW, Holloman GH, Feifel D. The psychopharmacology of agitation: consensus statement of the American Association for emergency psychiatry project BETA psychopharmacology workgroup. West J Emerg Med. (2012) 13:26-34. doi: 10.5811/westjem.2011.9.6866

10. Pacciardi B, Mauri M, Cargioli C, Belli S, Cotugno B, Di Paolo L, et al. Issues in the management of acute agitation: how much current guidelines consider safety? Front Psychiatry. (2013) 4:26. doi: 10.3389/fpsyt.2013.00026 
11. Gomez S, Dopheide J. Antipsychotic selection for acute agitation and time to repeat use in a psychiatric emergency department. J Psychiatr Pract. (2016) 22:450-8. doi: 10.1097/PRA.0000000000000186

12. Castle DJ, Udristoiu T, Kim CY, Sarosi A, Pidrman V, Omar $\mathrm{AN}$, et al. Intramuscular olanzapine versus short-acting typical intramuscular antipsychotics: comparison of real-life effectiveness in the treatment of agitation. World J Biol Psychiatry. (2009) 10:43-53. doi: 10.1080/15622970802688051

13. Baldaçara L, Diaz AP, Leite V, Pereira LA, Dos Santos RM, Gomes Júnior VP, et al. Brazilian guidelines for the management of psychomotor agitation. Part 2. pharmacological approach. Braz J Psychiatry. (2019) 41:324-35. doi: 10.1590/1516-4446-2018-0177

14. Patel MX, Sethi FN, Barnes TRE, Dix R, Dratcu L, Fox B, et al. Joint BAP NAPICU evidence-based consensus guidelines for the clinical management of acute disturbance: de-escalation and rapid tranquillisation. $J$ Psychopharmacol. (2018) 32:601-40. doi: 10.1177/0269881118776738

15. Paton C, Adams CE, Dye S, Fagan E, Okocha C, Barnes TR. The pharmacological management of acute behavioural disturbance: data from a clinical audit conducted in UK mental health services. J Psychopharmacol. (2019) 33:472-81. doi: 10.1177/0269881118817170

16. NICE. 2019 Surveillance of Violence and Aggression: Short-Term Management in Mental Health, Health and Community Settings (NICE Guideline NG10). (2019). p. 1-32. Available online at: https://www.nice.org.uk/guidance/NG10/ documents/surveillance-review-proposal

17. Wong AH, Taylor RA, Ray JM, Bernstein SL. Physical restraint use in adult patients presenting to a general emergency department. Ann Emerg Med. (2019) 73:183-92. doi: 10.1016/j.annemergmed.2018.06.020

18. Zeller SL, Rhoades RW. Systematic reviews of assessment measures and pharmacologic treatments for agitation. Clin Ther. (2010) 32:403-25. doi: 10.1016/j.clinthera.2010.03.006

19. Cañas F. Management of agitation in the acute psychotic patient-efficacy without excessive sedation. Eur Neuropsychopharmacol. (2007) 17(Suppl. 2):S108-14. doi: 10.1016/j.euroneuro.2007.02.004

20. Zeller S, Wilson M, Nordstrom K. Intramuscular midazolam, olanzapine, ziprasidone, or haloperidol for treating acute agitation. Ann Emerg Med. (2019) 73:422-3. doi: 10.1016/j.annemergmed.2018.11.019

21. Jin RO, Anaebere TC, Haar RJ. Exploring bias in restraint use: four strategies to mitigate bias in care of the agitated patient in the emergency department. Acad Em Med. (2021) 28:1061-6. doi: 10.1111/acem.14277

22. Gault TI, Gray SM, Vilke GM, Wilson MP. Are oral medications effective in the management of acute agitation? J Emerg Med. (2012) 43:854-9. doi: 10.1016/j.jemermed.2012.01.028

23. Mullinax S, Shokraneh F, Wilson MP, Adams CE. Oral medication for agitation of psychiatric origin: a scoping review of randomized controlled trials. J Emerg Med. (2017) 53:524-9. doi: 10.1016/j.jemermed.2017.04.026

24. Soliman E, Ranjan S, Xu T, Gee C, Harker A, Barrera A, et al. A narrative review of the success of intramuscular gluteal injections and its impact in psychiatry. Biodes Manuf. (2018) 1:161-70. doi: 10.1007/s42242-018-0018-x

25. Yap CYL, Taylor DMD, Kong DCM, Knott JC, Taylor SE, Sedation for Acute Agitation in Emergency Department Patients: Targeting Adverse Events (SIESTA) Collaborative Study Group. Risk factors for sedation-related events during acute agitation management in the emergency department. Acad Emerg Med. (2019). 26:1135-43. doi: 10.1111/acem.13826

26. Shenvi C, Kennedy M, Austin CA, Wilson MP, Gerardi M, Schneider S. Managing delirium and agitation in the older emergency department patient: the ADEPT tool. Ann Emerg Med. (2020) 75:136-45. doi: 10.1016/j.annemergmed.2019.07.023

27. Gerson R, Malas N, Feuer V, Silver GH, Prasad R, Mroczkowski MM. Best practices for evaluation and treatment of agitated children and adolescents (BETA) in the emergency department: consensus statement of the American Association for emergency psychiatry. West J Emerg Med. (2019) 20:409-18. doi: 10.5811/westjem.2019.1.41344

28. Niforatos JD, Wanta JW, Shapiro AP, Yax JA, Viguera AC. How should I treat acute agitation in pregnancy? Cleve Clin J Med. (2019) 86:243-7. doi: 10.3949/ccjm.86a.18041

29. Zun LS. Evidence-based review of pharmacotherapy for acute agitation. Part 1: onset of efficacy. J Emerg Med. (2018) 54:364-74. doi: 10.1016/j.jemermed.2017.10.011
30. Klein LR, Driver BE, Miner JR, Martel ML, Hessel M, Collins JD, et al. Intramuscular midazolam, olanzapine, ziprasidone, or haloperidol for treating acute agitation in the emergency department. Ann Emerg Med. (2018) 72:37485. doi: 10.1016/j.annemergmed.2018.04.027

31. Klein LR, Driver BE, Horton G, Scharber S, Martel ML, Cole JB. Rescue sedation when treating acute agitation in the emergency department with intramuscular antipsychotics. J Emerg Med. (2019) 56:484-90. doi: 10.1016/j.jemermed.2018.12.036

32. Zun LS. Evidence-based review of pharmacotherapy for acute agitation. Part 2: safety. J Emerg Med. (2018) 54:522-32. doi: 10.1016/j.jemermed.2017.11.031

33. Bak M, Weltens I, Bervoets C, De Fruyt J, Samochowiec J, Fiorillo A, et al. The pharmacological management of agitated and aggressive behaviour: a systematic review and meta-analysis. Eur Psychiatry. (2019) 57:78-100. doi: 10.1016/j.eurpsy.2019.01.014

34. Zareifopoulos N, Panayiotakopoulos G. Treatment options for acute agitation in psychiatric patients: theoretical and empirical evidence. Cureus. (2019) 11:e6152. doi: 10.7759/cureus.6152

35. Muir-Cochrane E, Oster C, Gerace A, Dawson S, Damarell R, Grimmer K. The effectiveness of chemical restraint in managing acute agitation and aggression: a systematic review of randomized controlled trials. Int J Ment Health Nurs. (2020) 29:110-26. doi: 10.1111/inm.12654

36. Ostinelli EG, Brooke-Powney MJ, Li X, Adams CE. Haloperidol for psychosisinduced aggression or agitation (rapid tranquillisation). Cochrane Database Syst Rev. (2017) 7:CD009377. doi: 10.1002/14651858.CD009377.pub3

37. Ostinelli EG, Jajawi S, Spyridi S, Sayal K, Jayaram MB. Aripiprazole (intramuscular) for psychosis-induced aggression or agitation (rapid tranquillisation). Cochrane Database Syst Rev. (2018) 1:CD008074. doi: 10.1002/14651858.CD008074.pub2

38. Pepa PA, Lee KC, Huynh HE, Wilson MP. Safety of risperidone for acute agitation and alcohol intoxication in emergency department patients. J Emerg Med. (2017) 53:530-5. doi: 10.1016/j.jemermed.2017.05.028

39. Pratts M, Citrome L, Grant W, Leso L, Opler LA. A single-dose, randomized, double-blind, placebo-controlled trial of sublingual asenapine for acute agitation. Acta Psychiatr Scand. (2014) 130:61-8. doi: 10.1111/acps. 12262

40. Gottlieb M, Schiebout J. What is the efficacy of droperidol for the management of acute psychosis-induced agitation? Ann Emerg Med. (2018) 71:141-3. doi: 10.1016/j.annemergmed.2017.05.005

41. Huf G, Coutinho ES, Adams CE, TREC Collaborative Group. Rapid tranquillisation in psychiatric emergency settings in Brazil: pragmatic randomised controlled trial of intramuscular haloperidol versus intramuscular haloperidol plus promethazine. BMJ. (2007) 335:869. doi: 10.1136/bmj.39339.448819.AE

42. Huf G, Alexander J, Gandhi P, Allen MH. Haloperidol plus promethazine for psychosis-induced aggression. Cochrane Database Syst Rev. (2016) 11:CD005146. doi: 10.1002/14651858.CD005146.pub3

43. Lim HK, Kim JJ, Pae CU, Lee CU, Lee C, Paik IH. Comparison of risperidone orodispersible tablet and intramuscular haloperidol in the treatment of acute psychotic agitation: a randomized open, prospective study. Neuropsychobiology. (2010) 62:81-6. doi: 10.1159/000315437

44. Zimbroff DL, Marcus RN, Manos G, Stock E, McQuade RD, Auby P, et al. Management of acute agitation in patients with bipolar disorder: efficacy and safety of intramuscular aripiprazole. J Clin Psychopharmacol. (2007) 27:171-6. doi: 10.1097/JCP.0b13e318033bd5e

45. Currier GW, Simpson GM. Risperidone liquid concentrate and oral lorazepam versus intramuscular haloperidol and intramuscular lorazepam for treatment of psychotic agitation. J Clin Psychiatry. (2001) 62:153-7. doi: 10.4088/JCP.v62n0303

46. Khokhar MA, Rathbone J. Droperidol for psychosis-induced aggression or agitation. Cochrane Database Syst Rev. (2016) 12:CD002830. doi: 10.1002/14651858.CD002830.pub3

47. Kwentus J, Riesenberg RA, Marandi M, Manning RA, Allen MH, Fishman RS, et al. Rapid acute treatment of agitation in patients with bipolar I disorder: a multicenter, randomized, placebo-controlled clinical trial with inhaled loxapine. Bipolar Disord. (2012) 14:31-40. doi: 10.1111/j.1399-5618.2011.00975.x

48. Dundar Y, Greenhalgh J, Richardson M, Dwan K. Pharmacological treatment of acute agitation associated with psychotic and bipolar disorder: a 
systematic review and meta-analysis. Hum Psychopharmacol. (2016) 31:26885. doi: 10.1002/hup. 2535

49. Reyad AA, Mishriky R. Asenapine: pharmacological aspects and role in psychiatric disorders. Psychiatr Danub. (2019) 31:157-61. doi: $10.24869 /$ psyd.2019.157

50. Bauer JØ, Stenborg D, Lodahl T, Mønsted MM. Treatment of agitation in the acute psychiatric setting. An observational study of the effectiveness of intramuscular psychotropic medication. Nord J Psychiatry. (2016) 70:599-605. doi: 10.1080/08039488.2016.1188982

51. Mantovani C, Labate CM, Sponholz A Jr, de Azevedo Marques JM, Guapo VG, de Simone Brito dos Santos ME, et al. Are low doses of antipsychotics effective in the management of psychomotor agitation? A randomized, rated-blind trial of 4 intramuscular interventions. J Clin Psychopharmacol. (2013) 33:306-12. doi: 10.1097/JCP.0b013e3182900fd6

52. Edge R, Argáez C. Droperidol for Agitation in Acute Care. Ottawa, ON: Canadian Agency for Drugs and Technologies in Health (2021). Available online at: https://www.ncbi.nlm.nih.gov/books/NBK571530/

53. Tran-Johnson TK, Sack DA, Marcus RN, Auby P, McQuade RD, Oren DA. Efficacy and safety of intramuscular aripiprazole in patients with acute agitation: a randomized, double-blind, placebo-controlled trial. J Clin Psychiatry. (2007) 68:111-9. doi: 10.4088/JCP.v68n0115

54. Amore M, D'Andrea M, Fagiolini A. Treatment of agitation with lorazepam in clinical practice: a systematic review. Front Psychiatry. (2021) 12:628965. doi: 10.3389/fpsyt.2021.628965

55. Gillies D, Sampson S, Beck A, Rathbone J. Benzodiazepines for psychosisinduced aggression or agitation. Cochrane database Syst Rev. (2013) CD003079. doi: 10.1002/14651858.CD003079.pub3

56. Williams AM. Coadministration of intramuscular olanzapine and benzodiazepines in agitated patients with mental illness. Ment Health Clin. (2018) 8:208-13. doi: 10.9740/mhc.2018.09.208

57. Wilson MP, MacDonald K, Vilke GM, Feifel D. A comparison of the safety of olanzapine and haloperidol in combination with benzodiazepines in emergency department patients with acute agitation. J Emerg Med. (2012) 43:790-7. doi: 10.1016/j.jemermed.2011.01.024

58. Wilson MP, Chen N, Vilke GM, Castillo EM, MacDonald KS, Minassian A. Olanzapine in ED patients: differential effects on oxygenation in patients with alcohol intoxication. Am J Emerg Med. (2012) 30:1196-201. doi: 10.1016/j.ajem.2012.03.013

59. Raveendran NS, Tharyan P, Alexander J, Adams CE, TREC-India II Collaborative Group. Rapid tranquillisation in psychiatric emergency settings in India: pragmatic randomised controlled trial of intramuscular olanzapine versus intramuscular haloperidol plus promethazine. BMJ. (2007). 335:865. doi: 10.1136/bmj.39341.608519.BE

60. Campillo A, MacDonald KS, Vilke GM, Wilson MP. 416 The B52 combination is not frequently used in emergency departments and causes a high proportion of patients to fall asleep. Ann Emerg Med. (2012) 60(Suppl.):S147. doi: 10.1016/j.annemergmed.2012.06.448

61. Sullivan N, Chen C, Siegel R, Ma Y, Pourmand A, Montano N, et al. Ketamine for emergency sedation of agitated patients: a systematic review and metaanalysis. Am J Emerg Med. (2020) 38:655-61. doi: 10.1016/j.ajem.2019.11.007

62. Mankowitz SL, Regenberg P, Kaldan J, Cole JB. Ketamine for rapid sedation of agitated patients in the prehospital and emergency department settings: a systematic review and proportional meta-analysis. J Emerg Med. (2018) 55:670-81. doi: 10.1016/j.jemermed.2018.07.017

63. Schneider A, Mullinax S, Hall N, Acheson A, Oliveto AH, Wilson MP. Intramuscular medication for treatment of agitation in the emergency department: a systematic review of controlled trials. Am J Emerg Med. (2021) 46:193-9. doi: 10.1016/j.ajem.2020.07.013

64. Cole JB, Klein LR, Mullinax SZ, Nordstrom KD, Driver BE, Wilson MP. Study enrollment when "preconsent" is utilized for a randomized clinical trial of two treatments for acute agitation in the emergency department. Acad Emerg Med. (2019) 26:559-66. doi: 10.1111/acem.13673

65. Calver L, Page CB, Downes MA, Chan B, Kinnear F, Wheatley L, et al. The safety and effectiveness of droperidol for sedation of acute behavioral disturbance in the emergency department. Ann Emerg Med. (2015) 66:2308.e1. doi: 10.1016/j.annemergmed.2015.03.016

66. Chan EW, Lao KSJ, Lam L, Tsui SH, Lui CT, Wong CP, et al. Intramuscular midazolam, olanzapine, or haloperidol for the management of acute agitation: a multi-centre, double-blind, randomised clinical trial. EClinicalMedicine. (2021) 32:100751. doi: 10.1016/j.eclinm.2021.100751

67. Chandrasena R, Dvoráková D, Lee SI, Loza N, Mosolov SN, Osváth P, et al. Intramuscular olanzapine vs. intramuscular short-acting antipsychotics: safety, tolerability and the switch to oral antipsychotic medication in patients with schizophrenia or acute mania. Int J Clin Pract. (2009) 63:1249-58. doi: 10.1111/j.1742-1241.2009.02116.x

68. Cole JB, Moore JC, Dolan BJ, O’Brien-Lambert A, Fryza BJ, Miner JR, et al. A prospective observational study of patients receiving intravenous and intramuscular olanzapine in the emergency department. Ann Emerg Med. (2017) 69:327-36.e2. doi: 10.1016/j.annemergmed.2016. 08.008

69. Breier A, Meehan K, Birkett M, David S, Ferchland I, Sutton V, et al. A double-blind, placebo-controlled dose-response comparison of intramuscular olanzapine and haloperidol in the treatment of acute agitation in schizophrenia. Arch Gen Psychiatry. (2002) 59:441-8. doi: 10.1001/archpsyc.59.5.441

70. Andrezina R, Josiassen RC, Marcus RN, Oren DA, Manos G, Stock E, et al. Intramuscular aripiprazole for the treatment of acute agitation in patients with schizophrenia or schizoaffective disorder: a doubleblind, placebo-controlled comparison with intramuscular haloperidol. Psychopharmacology. (2006) 188:281-92. doi: 10.1007/s00213-006-0 541-x

71. Zhang H, Wang G, Zhao J, Xie S, Xu X, Shi J, et al. Intramuscular ziprasidone versus haloperidol for managing agitation in Chinese patients with schizophrenia. J Clin Psychopharmacol. (2013) 33:178-85. doi: 10.1097/JCP.0b013e3182839612

72. Martel ML, Driver BE, Miner JR, Biros MH, Cole JB. Randomized doubleblind trial of intramuscular droperidol, ziprasidone, and lorazepam for acute undifferentiated agitation in the emergency department. Acad Emerg Med. (2021) 28:421-34. doi: 10.1111/acem.14124

73. San L, Estrada G, Oudovenko N, Montañés F, Dobrovolskaya N, Bukhanovskaya $\mathrm{O}$, et al. PLACID study: a randomized trial comparing the efficacy and safety of inhaled loxapine versus intramuscular aripiprazole in acutely agitated patients with schizophrenia or bipolar disorder. Eur Neuropsychopharmacol. (2018) 28:710-8. doi: 10.1016/j.euroneuro.2018.03.010

74. Lesem MD, Tran-Johnson TK, Riesenberg RA, Feifel D, Allen MH, Fishman R, et al. Rapid acute treatment of agitation in individuals with schizophrenia: multicentre, randomised, placebo-controlled study of inhaled loxapine. Br J Psychiatry. (2011) 198:51-8. doi: 10.1192/bjp.bp.110.0 81513

Author Disclaimer: The authors alone are responsible for the content and writing of this article. The views expressed in this article do not represent the views of the Department of Veterans Affairs or the U.S. government.

Conflict of Interest: The authors declare that the research was conducted in the absence of any commercial or financial relationships that could be construed as a potential conflict of interest.

The reviewer SZ declared a shared affiliation, with no collaboration, with the authors VS, EH, and RK at the time of the review.

Publisher's Note: All claims expressed in this article are solely those of the authors and do not necessarily represent those of their affiliated organizations, or those of the publisher, the editors and the reviewers. Any product that may be evaluated in this article, or claim that may be made by its manufacturer, is not guaranteed or endorsed by the publisher.

Copyright (c) 2021 Searles Quick, Herbst and Kalapatapu. This is an open-access article distributed under the terms of the Creative Commons Attribution License (CC $B Y)$. The use, distribution or reproduction in other forums is permitted, provided the original author(s) and the copyright owner(s) are credited and that the original publication in this journal is cited, in accordance with accepted academic practice. No use, distribution or reproduction is permitted which does not comply with these terms. 